\title{
A Comparative Strategy Using PI \& Fuzzy Controller for Optimization of Power Quality Control
}

\author{
Garima Sinha*, Pankaj Kumar Goswami, Sudhir Kumar Sharma \\ Research Scholar, Jaipur National University, Jaipur, India
}

\begin{tabular}{l}
\hline \hline Article Info \\
\hline Article history: \\
Received Dec 8, 2017 \\
Revised Feb 9, 2018 \\
Accepted Feb 24, 2018 \\
\hline
\end{tabular}

Keyword:

Active power filter

Harmonics

MATLAB/Simulation

PI/Fuzzy logic controller

Power quality

\begin{abstract}
This paper explores the analytical study and simulation of fuzzy logic controller and PI controller, to control the dc output voltage of shunt active power filter for harmonic reduction and power quality improvement in case of nonlinear load. Here we have exercised an effort to design and evaluate a converter to compensate the harmonics for 1-phase AC to DC bridge rectifier which is working as the main converter in unregulated mode. The work depends on the scheme where an ancillary converter is linked in shunt with the main or primary converter whose turn on and turn off time is controlled by an appropriate controller (pi/fuzzy logic) for harmonic compensation of the primary converter which is working as nonlinear load. The Model of converter is proposed on MATLAB ISIMULINK Software and the results are analyzed satisfactorily.
\end{abstract}

Copyright (C) 2018 Institute of Advanced Engineering and Science. All rights reserved.

Corresponding Author:

Garima Sinha,

Research Scholar, Jaipur National University, Jaipur, India.

Email: grmsinha@gmail.com

\section{INTRODUCTION}

Previously large industries in their mass applications were equipped with various nonlinear loads like arc furnaces, heavy rectifiers for electrolytic refining; variable frequency drives (VFD) etc. The harmonics generated by them were typically confined and sometimes addressed by some knowledgeable experts only. But now the times have changed. The problems related to harmonics are now common in not only automation but in domestic world as well [1]. As the no. of connected nonlinear loads is increased the overall sum of harmonics is also increased which can destroy components like circuit breakers and fuses, and also can cause utility meters to record wrong measurements. We use the nonlinear loads in our daily life that can generate harmonic currents some of them are computers, printers, fax machines, PLCs, TVs, refrigerators and electronic lighting ballasts. Personal computers also compliment of nonlinear loads since they associate with SMPS which is highly nonlinear.

Passive Filters can be used while working with a non-sinusoidal system to compensate the power quality problem but on account of their tuning for some particular frequencies they have limitations in their operating range. In this paper we have worked with active filter for harmonic reduction in line current [1].

Many researchers have worked in this area, in [1] researchers used sliding mode controlled and PI controlled shunt active power filter along with digital signal processor to mitigate harmonics in line current and it is observed that THD are reduced to $3.53 \%$ and $3.82 \%$ by using sliding mode controller and PI controller respectively. In [2] researchers utilized H-bridge inverter to reduce harmonics in line current and voltage for three different loads; resistive,resistive-inductive and motor load, the pattern search optimization algorithm is used to control the firing angle of inverter but did not give the exact value of reduced percentage THD. In [3] it is observed, for a distributed power single phase grid connected inverter using LCL filter which has the 
similar structure to that of an active power filter, the THD in line current is reduced from $69 \%$ to $1.83 \%$ with the help of quasi-proportional resonant controller.

In this paper first the proposed configuration of cicuit model is presented. After that the analysis of power quality is done first for linear load then for non-linear load. In order to reduce the harmonics and to improve the power quality for non-linear load applications, a synchronous link converter is designed which is analysed in section 5 and 6 using PI controller and fuzzy controller respectively. Simulation results are obtained for all four cases and compared at the last.

\section{PROPOSED CIRCUIT MODEL FOR PARALLEL CONVERTER SCHEME}

The Figure 1 presents the proposed circuit diagram of APF (Active Power Filter), depicting, parallel processing scheme of converters which is used for power quality improvement of uncontrolled nonlinear loads [5], which is the main objective of this paper. This scheme employs a 1-phase auxiliary converter known as SLC (Synchronous Link Converter) which works as an active power filter [5] connected in shunt with the main converter (bridge rectifier) feeding a resistive load along with a dc capacitor [6]. The SLC, made by switching device like IGBT whose gate pulse is controlled by an appropriate cont roller to control the turn on and turn off time of IGBT in such a manner that the greater part of active power is diverted to the main converter which is a diode bridge rectifier [7] along with R-load, while the current containing harmonics and reactive power required by the main converter flows through the ancillary or secondary converter (SLC). We have also focused on the strategy to create and verify the control of converter's parallel power processing scheme using MATLAB/Simulation. As soon as the angle between the source current and source voltage becomes zero it will cause the improvement of overall power factor and thus the power quality is also improved [8].Thus the combination of auxiliary converter (SLC) and nonlinear load can be considered as a pure resistive circuit $[7,8]$. The controlling of auxiliary converter should be such that the addition of input currents of auxiliary converter and main converter are in phase with source voltage and having sinusoidal waveform [8]. The controller we have used here is PI controller first and then fuzzy logic controller and after that compare the results of both.

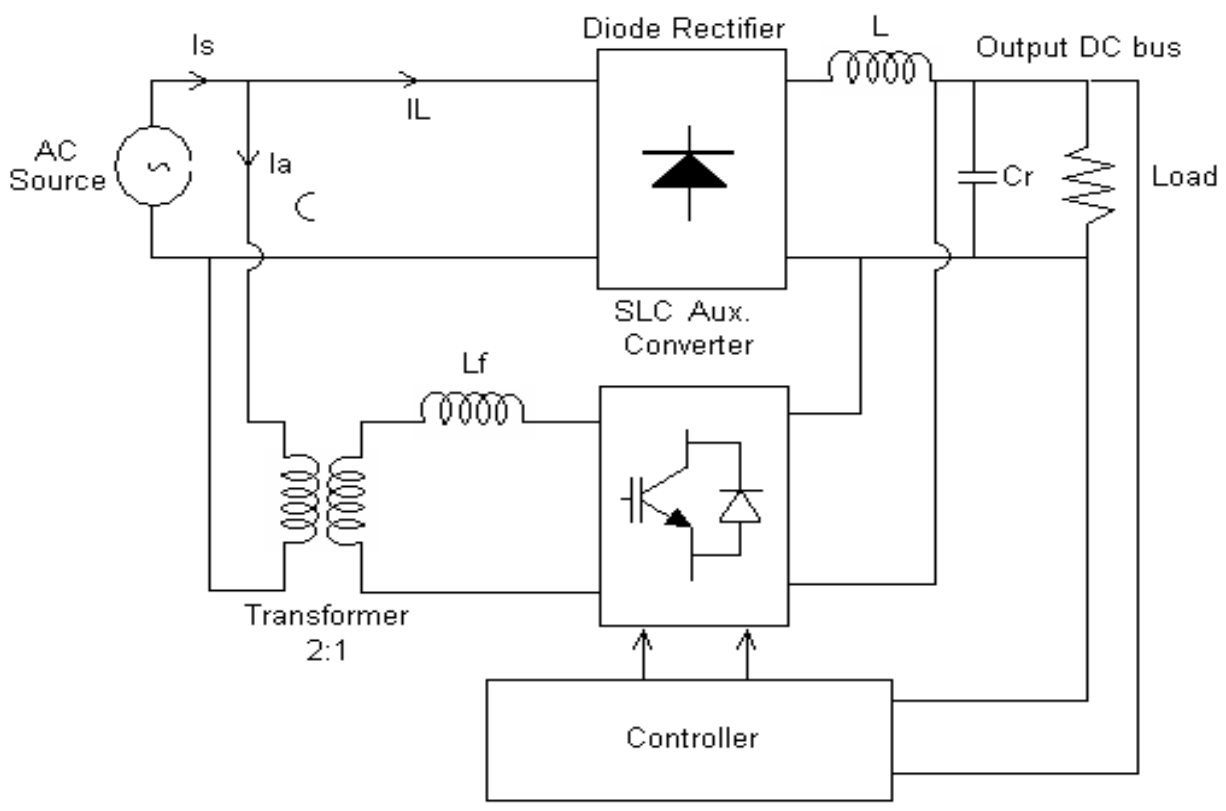

Figure 1. Block diagram of proposed model

\section{ANALYSIS OF POWER QUALITY WITH LINEAR LOAD APPLICATION}

When a sinusoidal supply is connected to linear load the line current and source voltage both have sinusoidal waveforms and in phase with each other which is quite observable in results of simulation of Simulink model shown in Figure 2(a),(b),(c)and (d). 


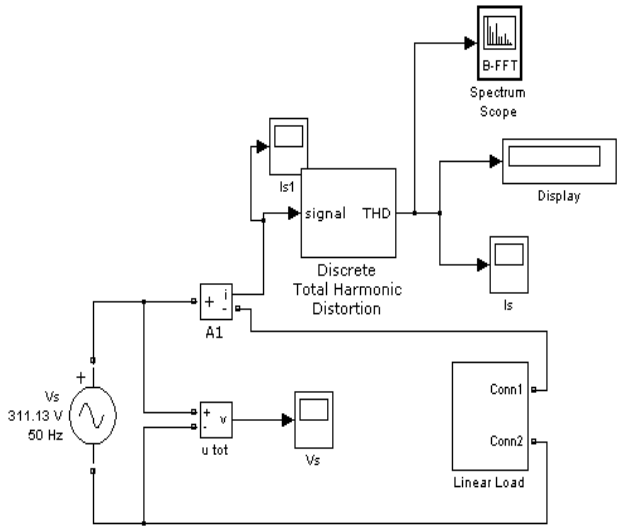

(a)Simulink model

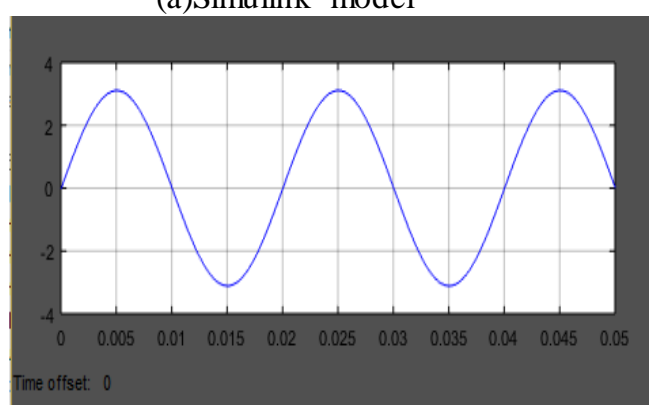

(c) source current

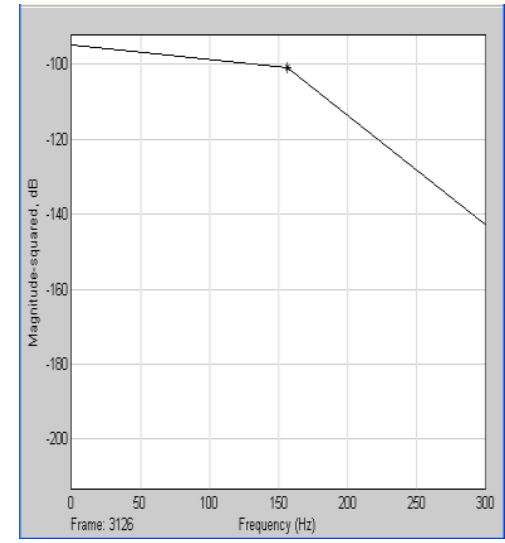

(b)THD display

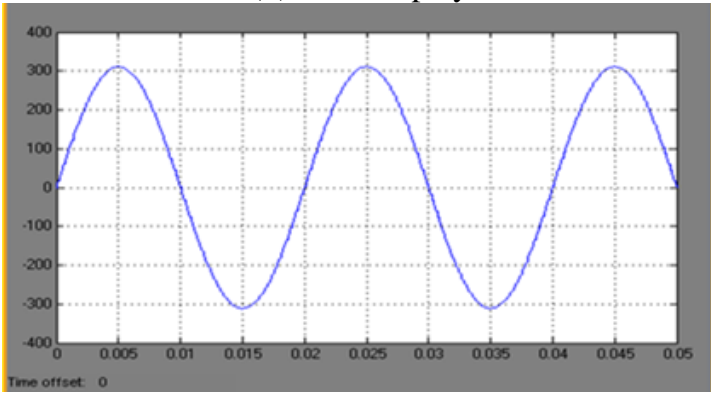

(d) source voltage

Figure 2. (a)Basic model on Simulink (b), (c) and (d) simulation results of linear load

\section{ANALYSIS OF POWER QUALITY WITH APPLICATION OF NONLINEAR LOAD}

Our When the same supply is fed to nonlinear load the line current will contain harmonics, source current and source voltage will not be in phase with each other and the power quality becomes poor as shown in Figure 3 here figure 3(a) is depicting the Simulink model of a non-linear load which is a diode bridge rectifier, and figure $3(\mathrm{~b})$, (c)and (d) are showing the simulation results such as the waveforms of source voltage, source current and total harmonic distortions.

It is very much clear from the simulated results that not only the wave form distortion is appeared but also the power factor distortion also becomes more significant. Hence the significant control over the quality of power is required to compensate the effects of nonlinearity in operating load. Many industrial applications are exhibiting the nonlinear adverse effects in its production area, as well as household appliance required to be adjusted with the tuned compensator to remove hazards from it operating parameter. This also helps in maintain durability of expensive components. The aim of the upcoming strategies is to rectify the hazardous harmonics form operating load current and overall up gradation of crucial parameters as per tradeoff. 


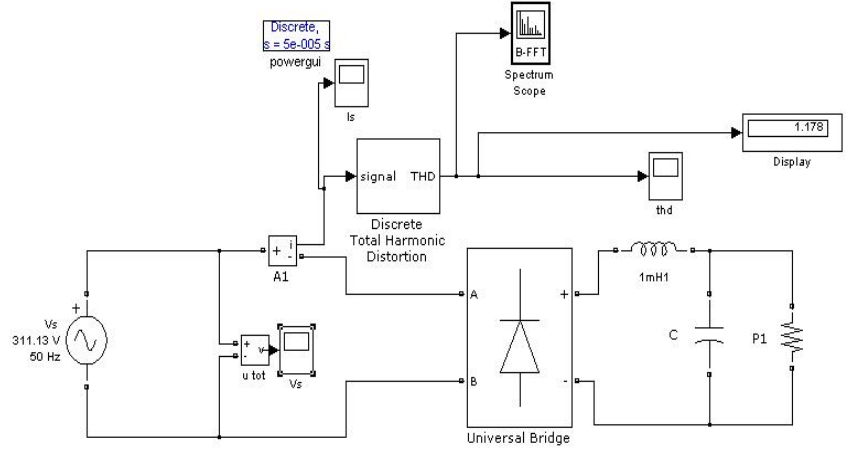

(a) Simulink model

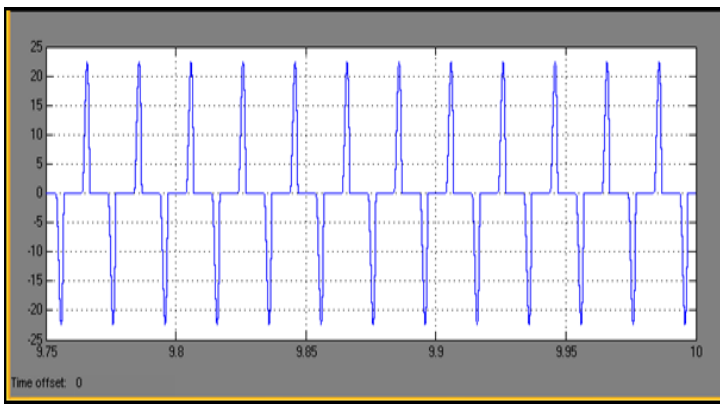

(c) Source current

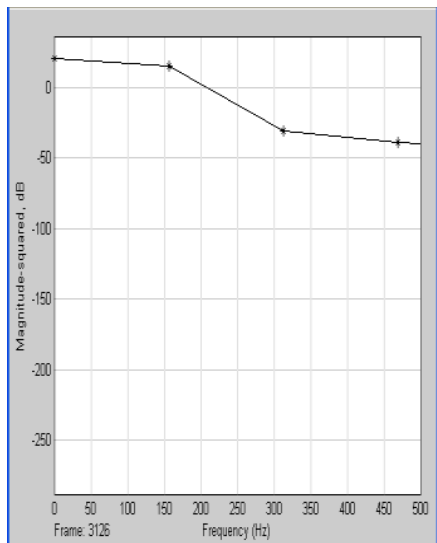

(b) THD Display

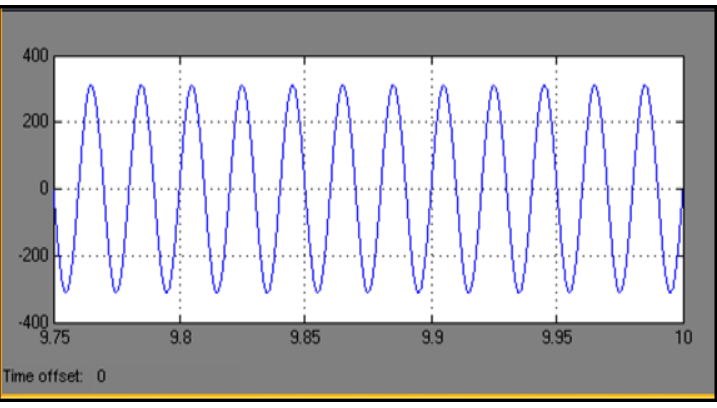

(d) Source voltage

Figure 3. (a) Simulink model (b),(c) and (d) Simulation results of nonlinear load [10]

\section{IMPROVEMENT OF POWER QUALITY OF NONLINEAR LOAD WITH PI CONTROLLER AND SLC}

When an ancillary or secondary converter (SLC) is connected in shunt with the nonlinear load (primary converter) and the turn on and turn off time of SLC is controlled using PI controller, the harmonics are reduced and the line current becomes sinusoidal again, thus the power quality is improved. Figure 4(a) is showing the simulation diagram here both the converters (auxiliary and main) are linked in parallel at both input and output terminals. Figure 4(b), (c)and (d) are showing simulation results of nonlinear load using PI controller [8]. From which we can see that the supply voltage and supply current both have sinusoidal waveforms without harmonic contents thus the power factor is improved and also the percentage of total harmonic distortion (\% THD) is reduced to $17.9 \%$ which was earlier $117.8 \%$ without the application of PI controller. But the \% THD can further be reduced; we did the same experiment again by using fuzzy controller in place of PI controller as explained in next section. 

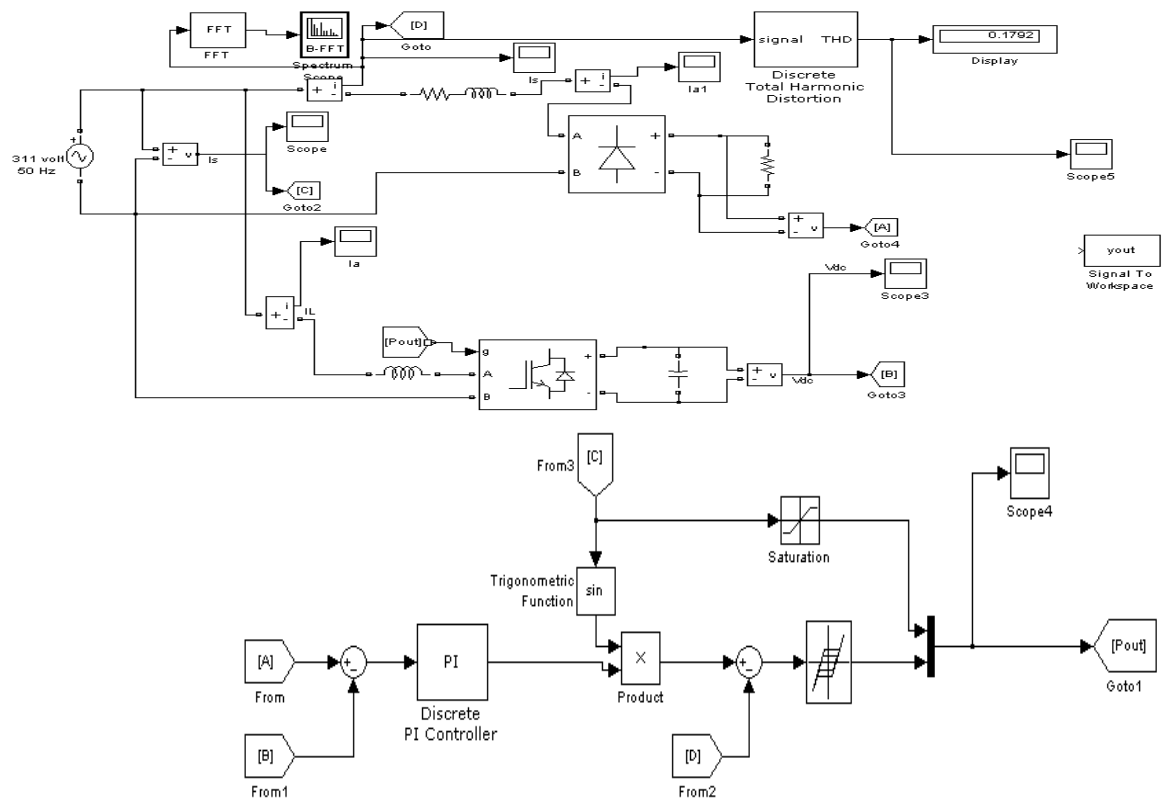

(a)simulink model

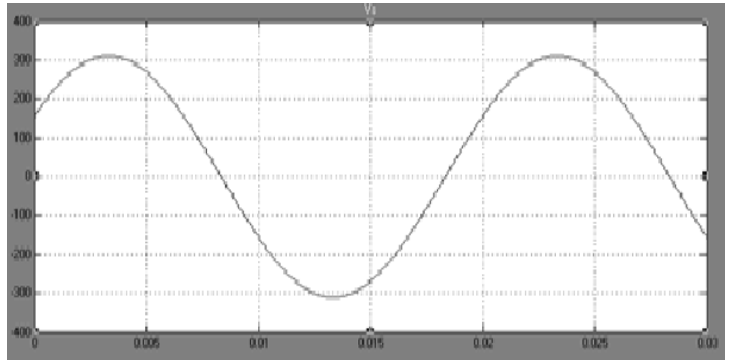

(b) Source voltage

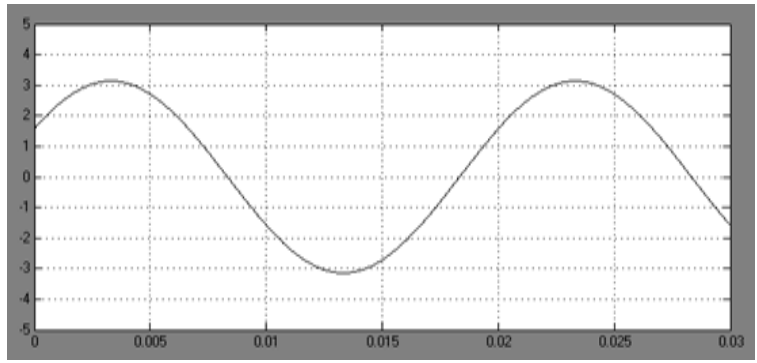

(b) Source voltage

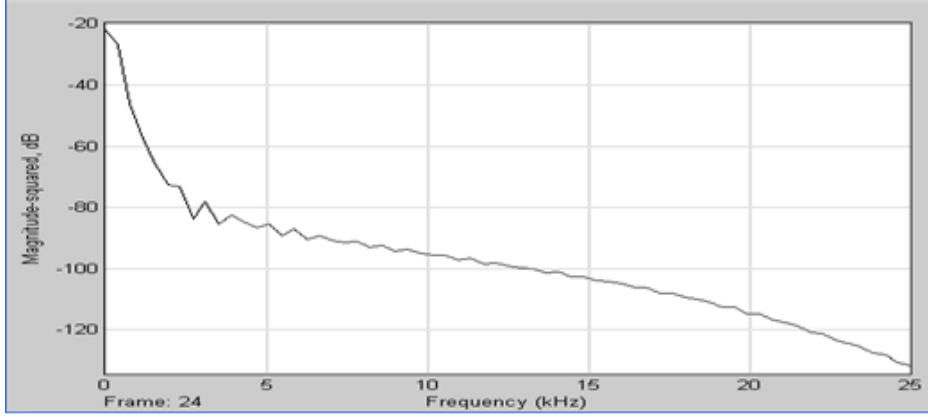

(d) THD display

Figure 4.(a)Simulink model (b),(c)and (d) Simulation results of nonlinear load with PI controller

\section{IMPROVEMENT OF POWER QUALITY OF NONLINEAR LOAD WITH FUZZY}

\section{CONTROLLER AND SLC}

If the fuzzy logic controller is used to control the gate pulse of the semiconductor device that is used in SLC [9] then the waveforms of supply voltage and supply current becomes sinusoidal and and the distortions in power quality which are presented in terms of $\% \mathrm{THD}$, reduced to $5 \%$, which can be depicted by Figure 5, indicating the Simulink model (a) and simulation result(b), (c)and (d) of nonlinear load using fuzzy logic controller. 


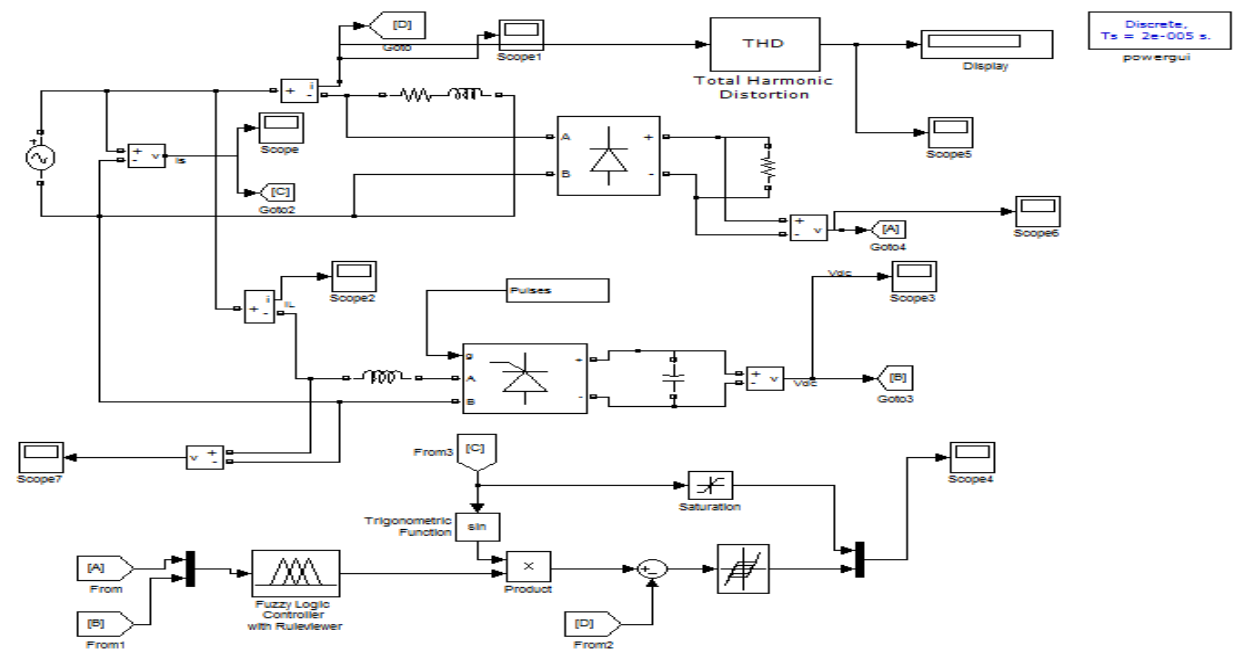

(a)Simulink model

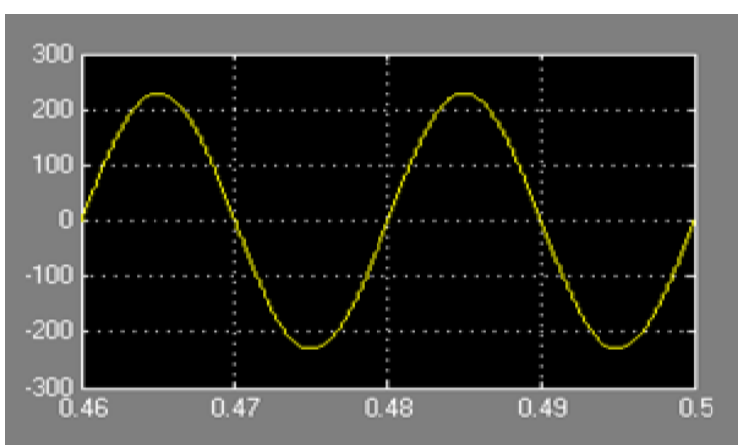

(b) Source voltage

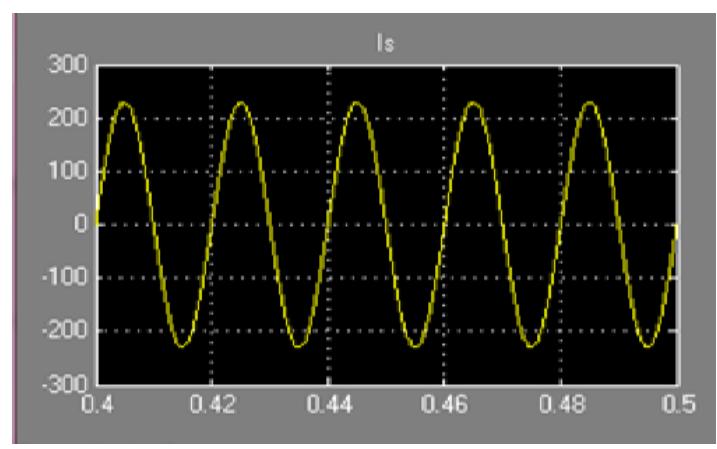

(c) Source current

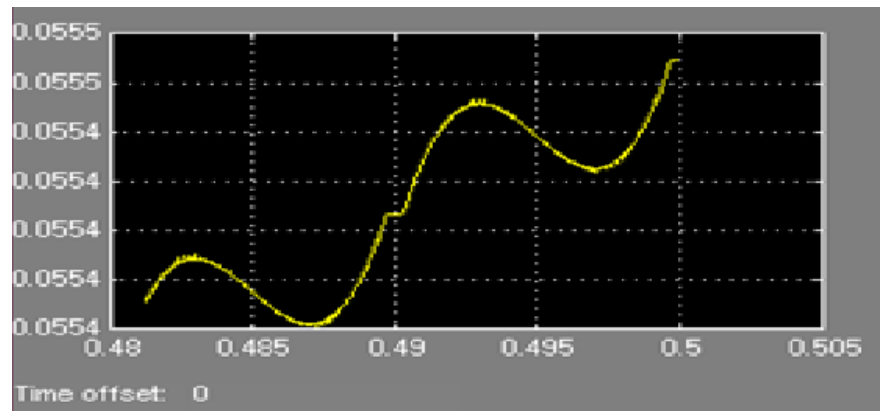

(d) THD display

Figure 5. (a) Simulink model (b), (c) and (d) Simulation results of nonlinear load with fuzzy controller

\section{RESULT AND DISCUSSION}

After the analysis of power quality in 4 cases; with linear load, with non-linear load, with non-linear load, SLC and PI controller, with non-linear load, SLC and Fuzzy controller, and various simulation results are obtained which are depicted by figure 2 to figure 5. The comparis on of various results is summeris ed in tabulated form, given by Table 1 . 


\begin{tabular}{lcc}
\multicolumn{2}{c}{ Table 1. Comparative Description of Power Quality Improvement } \\
\hline \multicolumn{1}{c}{ Load } & Feed voltage (Vs) & \multicolumn{1}{c}{ Line current (Is) } \\
\hline Linear load & $311.13 \mathrm{v}$ & 3.2 A, with no harmonic distortion \\
Nonlinear load & $311.13 \mathrm{v}$ & Approx.3.2A, significantly high THD (117\%) \\
Nonlinear load Using SLC and PI controller & $311.13 \mathrm{v}$ & $3.2 \mathrm{~A}$ with reduced THD (12\%) \\
Nonlinear load using SLC and fuzzy logic controller & $311.13 \mathrm{v}$ & 3.2 A, effectively high reduction in THD (5\%) \\
\hline
\end{tabular}

\section{CONCLUSION}

In this work we have tried to develop a model to reduce harmonics and thus to improve the power quality of nonlinear load using SLC (synchronous link converter) [6]. An implementation for PI control and fuzzy logic control has been done in the digital environment with the help of MATLAB software. It can be concluded that initially when we worked with linear load, the supply voltage and current were in phase with each other having sinusoidal waveform but as soon as the nonlinear load is applied, the supply current waveform became distorted thus power quality becomes poor. With the application of SLC along with PI and Fuzzy logic controller to control the turn on and turn off time of IGBT and after the simulation of designed model using MATLAB it has been found that the source current waveform became again sinusoidal with reduced distortions thus we got the improved power quality. Table 1 presents the analogous study of power quality control to compare the distortions in the four different cases.

\section{REFERENCES}

[1] M.T. Benchouia, I. Ghadbane,A. Golea, K.Srairi, M.H.Benbouzid. "Design and implementation of sliding mode and PI controllers based control for three phase shunt active power filter". Elsevier energy procedia. 2014;50:504511.

[2] Suresh N.1, R. Samuel Rajesh Babu. "Reduction of Total Harmonic Distortion in Cascaded H-Bridge Inverter by Pattern Search Technique". International Journal of Electrical and Computer Engineering (IJECE). 2017; 7(6): 3292-3298

[3] Jin Jiapei, Chen Tiantian1, Luo Ling1, Su Shaoze. "A Control Strategy for Single-phase Grid-Connected Inverter with Power Quality Regulatory Function". TELKOMNIKA (Telecommunication, Computing, Electronics and Control). 2014; 12(1): 225-233.

[4] R. Balamurugan, R. Nithya. "FC/PV Fed SAF with Fuzzy Logic Control for Power Quality Enhancement". International Journal of Power Electronics and Drive System (IJPEDS). 2015; 5(4): 470-476.

[5] B. Singh, K. Al-Haddad, and A. Chandra. "A review of active filters for power quality improvement". IEEE Trans. Ind. Electron. 1999; 46 (6): 960-971.

[6] Goswami G., Goswami P.K. "Simulation of Power Quality Control of Non-Linear Load using Fuzzy Controller at MATLAB". International Journal for Research in Science and Advance Technology. 2013; 3: 114-119.

[7] R.K. Tripathi, Chandreshver Pratap Singh. "Power Quality Control of Unregulated Non-linear loads". IEEE International Conference (ICPCES). Allahabaad, India. 2010; 1-6.

[8] Goswami, Garima and Goswami, Pankaj Kumar. "A PI-Controlled Synchronous Link Converter Scheme for Power Quality Control on Nonlinear Load”. IUP Journal of Electrical \& Electronics Engineering. 2013; 51310:9

[9] R.Belaidi,A. Haddouche, H.Guendouz. "Fuzzy logic controller based three-phase shunt active power filter for compensating harmonics and reactive power under unbalanced mains voltage”. published by Elsevier energy procedia. 2012; 18: 560-570.

[10] Abinaya, M., N. Senthilnathan, and M.Sabarimuthu. "Harmonic compensation asancillary service in PV inverter based residential distribution system". International Conference on Circuits Power and Computing Technologies, 2014; Nagercoil, India.

[11] J. Nastran, R. Cajhen, M. Seliger, and P. Jereb, "Active power filter for nonlinear AC loads," IEEE Trans. Power Electron.1994; 9: 92-96.

Bhim Singh, Brij N. Singh, Ambrish Chandra, Kamal Al-Haddad, Ashish Pandey, and Dwarka P. Kothari. "A Review of Single-Phase Improved Power Quality AC-DC Converters”. IEEE Trans. Ind. Electronics, 2003;50(4): 410-417 